\title{
Fixação esquelética externa tipo Ia (unilateral-uniplanar) para osteossíntese diafisária de úmero em pombos domésticos (Columba livia)
}

\author{
Type Ia (unilateral-uniplanar) external Skeletal fixation for treatment of humeral diaphysis \\ fracture in domestic pigeons (Columba livia)
}

\author{
Alessandro Moraes Leotte ${ }^{1}$ Alceu Gaspar Raiser ${ }^{2}$ Fabricio Arygoni Braga $^{3}$ \\ Luciene Krauspenhar ${ }^{3}$ Sheyla Francheska Camargo ${ }^{4}$ Fabiola Niederauer Flores $^{4}$ Kléber Gomes $^{4}$ \\ Ricardo Simões Scherer ${ }^{5}$
}

RESUMO

Das várias patologias que podem acometer as aves, são mais freqüentes as fraturas de ossos longos das asas e dos membros pélvicos. Este experimento teve como objetivo observar, por meio de exames clínicos, histológicos e radiográficos, a resposta cicatricial óssea ao uso do fixador externo tipo Ia (unilateral-uniplanar) na redução aberta de fratura diafisária, de úmero em pombos domésticos (Columba livia). Foram estudados 14 pombos com peso variando entre 290 e 420 gramas. A fratura foi realizada na diáfise do úmero direito e, logo após, estabilizada com aparelho de fixação externa tipo Ia, utilizandose, como barra de fixação, o acrílico autopolimerizável. O tempo médio para o completo desaparecimento da linha de fratura foi

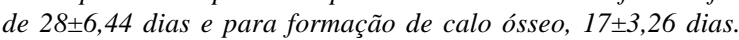
As aves, mesmo com o aparelho de fixação, retornaram ao vôo

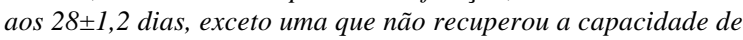
vôo. A técnica de fixação externa demonstrou ser eficaz para o tratamento de fraturas diafisárias de úmero em pombos domésticos.

Palavras-chave: cirurgia, fratura, ortopedia.

\section{ABSTRACT}

Among the various pathologies that can inflict birds, the long bones fractures of the wings, and pelvic members are more commom. Fourteeen domestic pigeons (Columba livia) weighing 290 to 420g, were submitted to open reduction of humeral diaphysis fracture with external fixator type Ia (unilateral-uniplanar) in order to evaluate the clinical, histological and radiographic evolution of the bone healing. The external fixator device was stabilized with methilmetacrylate acrylic. The average time necessary to the complete disappearance of the fracture line by radiographic evaluation was $28 \pm 6.44$ days. The bone callus was identified at $17 \pm 3.26$ postoperative days. The birds returned to flying in $28 \pm 1.2$ days yet with the fixation device and only one did not recovere the flying abillity. The external fixation technique is an efficient method to treat diaphiseal humeral fracture in domestic pigeons.

Key words: surgery, fractures, ortophaedia.

\section{INTRODUÇÃO}

O úmero dos pombos domésticos sofre, freqüentemente, fratura iatrogênica devido a características, como córtex umeral fino com alto conteúdo de cálcio; significativo diâmetro medular; trabéculas ósseas muito finas e esparsas ao longo do seu comprimento e a falta de osso denso nas metáfises WAN et al. (1994) e WEST et al. (1996).

Ao avaliar 51 osteossíntese de úmero em aves, REDIG (1986) observou que apenas 18 fraturas (35\%) haviam consolidado e 12 aves (24\%) recuperaram a capacidade de voar. Isto, para LEVITT

\footnotetext{
${ }^{1}$ Médico Veterinário, Rua Arquimimo, 432, 9550-000,Tramandaí-RS. Autor para correspondência. E-mail: Leottemv@ bol.com.br ${ }^{2}$ Orientador, Professor Titular, Doutor, Programa de Pós-graduação em Medicina Veterinária (PPMV), Universidade Federal de Santa Maria (UFSM).

${ }^{3}$ Aluno do PPMV, UFSM.

${ }^{4}$ Aluno de graduação de Medicina Veterinária, UFSM.

${ }^{5}$ Aluno de graduação em Medicina Veterinária da UFSM, Bolsista de Iniciação Científica da Fundação de Amparo à Pesquisa do Rio Grande do Sul (FAPERGS), Processo 0151550-0.
} 
(1989), deve-se à baixa resistência do úmero das aves em relação à carga aerodinâmica a que são submetidos e à presença de cortical quebradiça, restringindo, assim, a colocação de implantes como parafusos e hemitalas de Kirschner-Ehmer.

Os objetivos do reparo de fraturas em pássaros são idênticos ao dos mamíferos. O primeiro importante passo é alinhar os fragmentos, manter a biomecânica da estrutura afetada e obter rígida estabilização após redução. Esta estabilização deve retornar de forma rápida, com firme formação de calo ósseo, permitir rápido desenvolvimento dos vasos sanguíneos e minimizar os danos às estruturas adjacentes como nervo, vasos e músculos, MACCOY (1991). BUSH (1977) complementa que o método de osteossíntese deve ser tolerado pelo pássaro, proporcionar rígida estabilização, curto tempo cirúrgico e anestésico, pequena formação de calo ósseo e rápido retorno ao uso funcional do membro.

A fratura de úmero em aves exige redução anatômica dos fragmentos e um ótimo alinhamento rotacional para garantir o perfil aerodinâmico da asa e o retorno ao vôo (BENNET \& KUZMA, 1992; WAN et al., 1994). De acordo com LEVITT (1989), a força rotacional exercida pelos fortes músculos e tendões das asas, pode causar deformidade de torção e interferir na capacidade de voar.

Podem-se utilizar vários tipos de materiais para osteossíntese de ossos longos das aves como pinos intramedulares (GAIGA, 2002) ou fixadores esqueléticos externos tipo I ou tipo II (EGGER, 1996; RUPLEY, 1999; ALIEVE, 2000), ou até mesmo, materiais alternativos como os descritos por ERDMANN et al. (2002), que utilizaram agulhas de calibre $25 \times 8,40 \times 12$ e $40 \times 16$ como pinos intramedulares.

O aparelho de Kirschner-Ehmer, com algumas modificações, pode ser usado no tratamento de fraturas em aves. $\mathrm{O}$ peso do dispositivo deve ser reduzido, utilizando-se pinos não maiores que $20 \%$ do diâmetro do osso e com uma barra de conexão leve (MACCOY, 1991).

O aparelho de Kirschner-Ehmer deve permitir o uso controlado do membro fraturado durante o período de convalescença, porque pequenos movimentos minimizam a atrofia por desuso com uma maior rapidez ao retorno normal da função (LEVITT, 1989). Para BENNET \& KUZMA (1992), o uso prolongado da imobilização externa em aves pode levar à "doença da fratura", sendo essa uma das principais causas de fracasso em ortopedia aviária quando o uso do membro é necessário.
PUTNEY et al. (1983) não obtiveram consolidação óssea em fraturas de úmero de pombos mal estabilizadas, e ALIEVI (2000), utilizando fixador externo tipo I ou II, em fraturas de tíbio tarso de pombos, observou consolidação óssea em seis semanas, ao mesmo tempo em que WILLIANS et al. (1987) verificaram consolidação em fraturas diafisária de úmero com aparelho de fixação tipo IA. GAIGA (2002) obteve, como tempo médio, 45 dias para consolidação óssea em fraturas de úmero de pombos, utilizando xenoenxerto ósseo como pino intramedular.

Enquanto YAMAZOE et al. (1994) relatam que seus pombos de experimentação, submetidos à redução de fratura umeral, com fixador externo, recuperaram a capacidade de voar num período de seis semanas, GAIGA (2002) obteve uma recuperação do vôo num período aproximado de 24 dias, utilizando xenoenxerto ósseo como pino intramedular. KUZMA (1995) e GAIGA (2002) recomendam a abordagem cirúrgica ventral para exposição da diáfise umeral de aves, por ser de fácil execução e para evitar estruturas nobres como o nervo radial. Esses autores comentam que a abordagem dorsal é preferida somente quando se deseja exposição da diáfise proximal do úmero.

Este experimento teve como objetivo avaliar, por meio de exames clínicos, histológicos e radiográficos, a resposta cicatricial óssea frente ao uso do fixador esquelético externo tipo Ia, em redução aberta de fratura diafisária de úmero em pombo doméstico (Columba livia).

\section{MATERIAL E MÉTODOS}

Quatorze pombos domésticos (Columba livia) com pesos variando entre 290 e $420 \mathrm{~g}$, sem identificação de gênero, foram alojadas individualmente, ou em pares, em gaiolas de $1 \mathrm{~m}^{3}$, onde permaneceram por, no mínimo, 15 dias para adaptação ao local e alimentação. Após jejum prévio de duas horas, cada ave foi encaminhada ao Centro Cirúrgico do Laboratório de Cirurgia Experimental do Hospital Veterinário da UFSM, onde recebeu uma dose de $10 \mathrm{mg} / \mathrm{kg}$ de enrofloxacina intramuscular na região do peito.

Cada ave foi colocada sobre uma bolsa térmica, com temperatura ao redor de $38^{\circ} \mathrm{C}$ e recebeu, como medicação pré-anestésica, tartarato de butorfanol $\left(0,4 \mathrm{mg} \mathrm{kg}^{-1}\right)$, pela via intramuscular, sendo induzida, na seqüência, com halotano por máscara. Em seguida, foi intubada com sonda orotraqueal e mantida em plano de anestesia cirúrgica pela inalação de halotano em vaporizador universal, vaporizado em oxigênio $100 \%$, com volume de 0,5 litro por minuto, 
em circuito semi-aberto. Os batimentos cardíacos foram monitorizados por Doppler ultra sônico, fixado na região tíbio társica. Após cada ave entrar em plano de anestesia cirúrgica, foi realizada a remoção manual das penas localizadas na região do trato umeral, seguida de anti-sepsia do local com gluconato de clorexidina 4\%, conforme indicado por ALIEVI (2000) e GAIGA (2002).

Com a ave em decúbito lateral esquerdo, foi realizada a diérese aguda de pele e tecido subcutâneo, na face dorsal da diáfise umeral, por aproximadamente $3,5 \mathrm{~cm}$. Após a visualização do úmero e afastamento do nervo radial, foi realizada osteotomia transversa completa com serra oscilatória na região de sua diáfise. Quatro pinos de Kirschner (1mmØ), dois proximais e dois distais ao foco da fratura, foram introduzidos com a ajuda de um introdutor manual de Jacob, formando um ângulo de aproximadamente 70 graus em relação ao eixo longitudinal do osso. Os pinos foram inseridos pela linha de incisão, atravessando ambas as corticais, sendo que a segunda cortical era transpassada o suficiente para permitir a sustentação dos pinos sem atingir a musculatura e a pele na face ventral da asa, de modo a configurar um fixador esquelético externo tipo Ia (unilateral-uniplanar). Em seguida à redução da fratura, os pinos foram conectados com uma barra de acrílico autopolimerizável na face dorsal do úmero. A distância mantida entre a pele e o acrílico foi de aproximadamente $5 \mathrm{~mm}$ e a ferida cirúrgica foi suturada em plano único, com categute cromado 4-0, em pontos de Wolf.

Todas as aves receberam três doses de $2,5 \mathrm{mg} \mathrm{kg}^{-1}$ de flunixin meglumine, pela via intramuscular, a cada $24 \mathrm{~h}$, como terapia analgésica e antiinflamatória. Elas foram avaliadas semanalmente para verificação das condições do aparelho de fixação externo na área cirúrgica.

Nas avaliações radiográficas, foi observado o alinhamento da fratura, presença de calo e tempo de consolidação óssea pelo desaparecimento completo da linha de fratura. As incidências foram realizadas nas posições antero-posterior e médio-lateral, no pósoperatório imediato e, semanalmente, até a verificação da inexistência da linha de fratura ou nos tempos preestabelecidos para coleta dos úmeros para avaliação histológica.

Nos tempos 15, 30, 45, 60 e 90 dias, após o procedimento cirúrgico, foram sacrificadas duas aves, utilizando-se uma dose total de $75 \mathrm{mg} \mathrm{kg}^{-1}$ de tiopental sódico, pela via intracelomática. Após este procedimento, o úmero foi removido para avaliação. Macroscopicamente, observou-se mobilidade óssea ou não no local de osteotomia, deformidade angular e/ou rotacional, e a presença de reabsorção óssea no local de inserção dos pinos. Após, o úmero foi fixado em solução de formol líquido a $10 \%$, sofrendo posterior descalcificação por ácido nítrico $10 \%$. Um fragmento de aproximadamente $2,5 \mathrm{~cm}$, cujo ponto central era a antiga fratura, foi processado pela técnica rotineira de inclusão em parafina e corado por hematoxilinaeosina, para avaliação microscópica.

\section{RESULTADOS E DISCUSSÃO}

O uso de analgésicos no pós-operatório, como preconizado por JENKINS (1992) e RUPLEY (1999), foi eficaz, pois as aves mantiveram-se alertas e alimentando-se normalmente, demonstrando a ausência de dor. A administração de flunixin meglumine, na dose de $2,5 \mathrm{mg} \mathrm{kg}^{-1}$, proposta por ALIEVI (2000) e GAIGA (2002), uma vez ao dia, por três dias consecutivos foi suficiente para controle da dor.

Diferindo da recomendação de KUZMA (1995) e GAIGA (2002), a abordagem cirúrgica dorsal à diáfise umeral demonstrou-se eficaz para o tratamento de fraturas diafisárias de úmero, não sendo encontrado problema para isolar estruturas como o nervo radial. Além de a abordagem dorsal evitar um maior número de vasos, permitiu a exposição de todo o osso.

O fio categute cromado 4-0 ofereceu sustentação apropriada na redução dos planos anatômicos, isento de qualquer complicação, a um custo significativamente menor. Apresentou baixa reação inflamatória e já não estava presente na quarta semana de pós-operatório, demonstrando ser uma boa opção para sutura em aves, embora BENNET (1992), após comparar cinco tipos de fio, tenha aconselhado o uso da poligalactina 910 .

A colocação dos pinos, através da incisão cirúrgica, facilitou a fixação dos mesmos e, embora não seja aconselhada por EGGER (1996), por dificultar a oclusão da ferida, pois o uso da sutura de Wolf, em plano único, é facilmente efetuada sob a barra de acrílico. A presença dos pinos entre as bordas da ferida cirúrgica podem ser causa de deiscência em mamíferos, no entanto, nos pombos, não houve essa complicação, devido à rápida cicatrização nessa espécie.

Não houve recorrência de fraturas ou afrouxamento do aparelho de fixação apesar das características anatômicas do úmero citadas por WAN et al. (1994), o que demonstra que, mesmo com o córtex umeral fino e quebradiço, o método utilizado é eficaz para osteossíntese desse osso. Este tipo de aparelho permite o uso do membro durante o período de recuperação, minimiza a atrofia por desuso e oferece recuperação funcional da asa precocemente, 
como aconselhado por LEVITT (1989); isso evita a "doença da fratura" descrita por BENNET \& KUZMA (1992) e KUZMA (1995) que é uma das maiores causas de falha de osteossíntese em aves, em conseqüência da imobilização externa prolongada.

A formação de um calo ósseo pequeno aos $17 \pm 3,26$ dias (Tabela 1) indica a rígida estabilização que qualquer tipo de osteossíntese deve proporcionar, tanto em mamíferos como em aves. Num estudo histomorfométrico e angiográfico de úmero em

Tabela 1- Tempo necessário para a formação de calo ósseo e consolidação da fratura e retorno ao vôo de pombos domésticos (Columba livia) submetidos à osteossíntese de úmero por fixação esquelética tipo Ia e suas respectivas médias e desvio padrão.

\begin{tabular}{|c|c|c|c|}
\hline $\begin{array}{l}\text { Número } \\
\text { da ave }\end{array}$ & $\begin{array}{l}\text { Tempo para a } \\
\text { formação de calo } \\
\text { ósseo (dias) }\end{array}$ & $\begin{array}{l}\text { Tempo para a } \\
\text { consolidação da } \\
\text { fratura (dias) }\end{array}$ & $\begin{array}{c}\text { Tempo para as } \\
\text { aves retornarem } \\
\text { ao vôo (dias) }\end{array}$ \\
\hline 01 & 21 & 30 & 28 \\
\hline 02 & 21 & 21 & 28 \\
\hline 03 & S/ calo & 15 & - \\
\hline 04 & 15 & 21 & 28 \\
\hline 05 & 15 & 28 & 29 \\
\hline 06 & 15 & 28 & 28 \\
\hline 07 & 21 & 35 & 28 \\
\hline $08^{*}$ & - & - & - \\
\hline 09 & 15 & 35 & 28 \\
\hline 10 & 14 & 35 & 28 \\
\hline 11 & 14 & 21 & 28 \\
\hline $12 *$ & - & - & - \\
\hline 13 & 14 & 28 & 28 \\
\hline 14 & 21 & 28 & 29 \\
\hline $\bar{x} \pm s$ & $17 \pm 3,26$ & $28 \pm 6,44$ & $281 \pm$ \\
\hline
\end{tabular}

pombos, WEST et al. (1996) observaram que o calo periosteal é superior ao endosteal, com formação de extenso calo cartilaginoso, explicando assim a falta de visualização radiográfica do mesmo aos 15 dias de pós-operatório (Figura 1A).

Um pombo não recuperou o uso funcional do membro, pois a epífise distal sofreu rotação em um ângulo aproximado de $90^{\circ}$, demonstrando que a fratura de úmero exige uma perfeita redução anatômica, com alinhamento rotacional para garantir o perfil aerodinâmico da asa preconizado por BENNET \& KUZMA (1992) e WAN et al. (1994).

As modificações sugeridas por MACCOY (1991), no aparelho de fixação das aves, foram levadas em consideração, pois o peso aproximado de quatro gramas foi suportado facilmente pelas aves, que não apresentaram dificuldade em movimentar as asas e conseguir alçar vôo aos 28 dias de pós-operatório. Esse período é superior aos encontrados por YAMAZOE et al. (1994) e GAIGA (2002) que tiveram suas aves retornando ao vôo em torno de 24 dias, na osteossíntese com pino intramedular.

O sucesso obtido no presente experimento foi significativamente superior ao sucesso encontrado por LEVITT (1989) e PUTNEY et al. (1983). Nos estudos de LEVITT (1989), somente 18 de 51 osteossínteses consolidaram e de PUTNEY et al. (1983) não houve consolidação óssea umeral por má estabilização. O método aqui proposto assegura completa recuperação desde que se mantenha o adequado alinhamento ósseo.

O tempo médio da consolidação da fratura de 28 $\pm 6,44$ dias (Tabela 1), sendo considerado o desaparecimento da linha de fratura (Figura 1B), foi

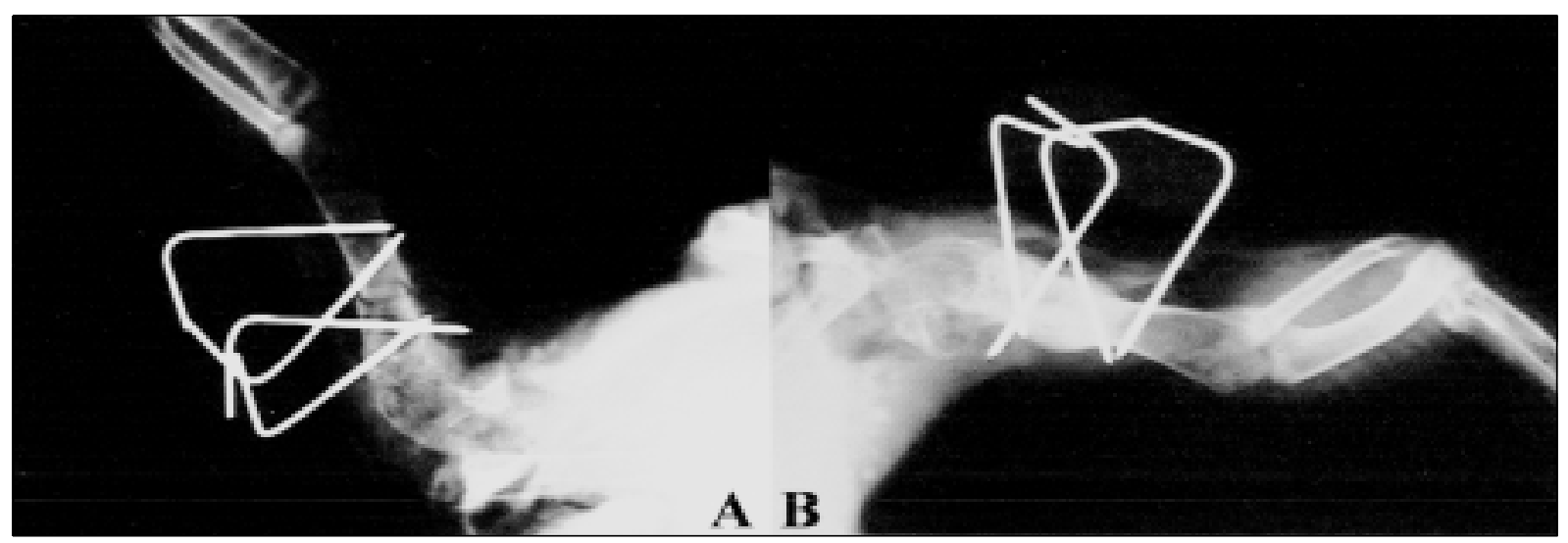

Figura 1 - (A) Imagem radiográfica no pós-operatório com 15 dias de evolução da osteossíntese de úmero em pombos (Columba livia) utilizando-se fixador esquelético externo tipo IA. Observar correto alinhamento e aposição, ausência de calo ósseo e presença da linha de fratura. (B) Imagem radiográfica no pós-operatório com 28 dias de evolução da osteossíntese, em que se observa correto alinhamento, presença de calo ósseo pequeno e ausência da linha de fratura.

Ciência Rural, v.34, n.6, nov-dez, 2004. 
menor do que o encontrado por WILLIANS et al. (1987), que utilizaram o mesmo aparelho de fixação para estabilização de fratura de úmero em pombos, e de ALIEVI (2000) e GAIGA (2002) que realizaram procedimentos diferenciados aos deste experimento, pois, no desaparecimento da linha de fratura, o aparelho de fixação era removido.

Pela análise histológica, verificou-se que as aves, aos 15 dias, apresentaram no local de inserção dos pinos e na linha de cicatrização óssea, predominância de tecido fibrocartilaginoso, como citado por WILLIANS et al. (1987). Esse resultado explica a falta de radiopacidade do calo ósseo nessa fase evolutiva, indo ao encontro da afirmação de ALIEVI (2000) e GAIGA (2002), de que, devido a esse calo cartilaginoso, os sinais clínicos de consolidação óssea ocorrem antes dos sinais radiográficos.

Aos 30 dias de pós-operatório, as amostras apresentaram alteração de calo ósseo fibrocartilaginoso para osso trabecular, com alguma remodelação óssea, caracterizando a rigidez observada macroscopicamente, no momento da coleta. Em uma ave foi detectado seqüestro ósseo na região de penetração dos pinos devido à alguma mobilidade no local, que não foi evidenciado radiograficamente e não alterou o movimento e uso funcional da asa.

Com 45 dias de evolução, observou-se grande atividade de remodelação óssea. Em um pombo, a atividade osteoclástica exuberante não foi suficiente para apresentar alteração radiográfica e o discreto desalinhamento ósseo não alterou o uso do membro para o vôo. Aos 60 dias, a ave que apresentou rotação de $90^{\circ}$ da porção distal da fratura no momento da cirurgia, evidenciava microscopicamente um significante espaçamento periosteal, formado por tecido conjuntivo denso sem a consolidação do processo cicatricial, o que corrobora com BENNET \& KUZMA (1992), os quais citam a necessidade do correto alinhamento dos segmentos fraturados para se obter apropriada cicatrização óssea. Nas aves com 90 dias de evolução, a remodelação óssea estava praticamente completa.

\section{CONCLUSÃO}

Com estes resultados, conclui-se que o aparelho de fixação esquelética externa tipo Ia (unilateral-uniplanar) oferece adequada estabilização para fratura diafisária de úmero em pombos domésticos. O retorno funcional depende de adequada redução dos segmentos fraturados e a estabilização da fratura ocorre precoce e anteriormente à evidência radiográfica devido à formação de calo ósseo fibrocartilaginoso.

\section{REFERÊNCIAS BIBLIOGRÁFICAS}

ALIEVI, M.M. Redução fechada e fixação esquelética tipo I ou II para tratamento de fratura de tibiotarso em pombos domésticos (Columba Livia). 2000. 38f. Dissertação (Mestrado em cirurgia) - Programa de Pós-graduação em Medicina Veterinária, Universidade Federal de Santa Maria.

BENNET, R.A. Patient preparation for avian surgery. In: ACVS VETERINARY SYMPOSIUM, 1992, Miami, Florida. Proceedings... Miami : The American College of Veterinary Surgeons, 1992. p.622-624.

BENNET, R.A.; KUZMA, A.B. Fracture management in birds. Journal of Zoo and Wildlife Medicine, v.23, p.5-38, 1992.

BUSH, M. External fixation of avian fractures. Journal of the American Animal Hospital Assiciation, v.171, p.943-946, 1977.

EGGER, E.L. Fixação esquelética interna. In: SLATTER D. Manual de cirurgia de pequenos animais. 2. ed. São Paulo : Manole, 1996. V.2. Cap.123, p.1944-1966.

ERDMANN, R.L. et al. Utilização de materiais alternativos para cirurgias ortopédicas em aves silvestres na clínica veterinária Santa Clara, Cascavel - Paraná. In: CONGRESSO DA SOCIEDADE DE ZOOLÓGICOS DO BRASIL, 26. ENCONTROS DE ZÔOS DO MERCOSUL, 2., 2002, Porto Alegre. Anais... POA : Sociedade de Zoológicos do Brasil, 2002. p.33

GAIGA, L.H. Osteossíntese de úmero por xenoenxerto ósseo preservado em glicerina $98 \%$ ou mel em pombos domésticos (Columba livia). 2002. 45f. Dissertação (Mestrado em Cirurgia) - Programa de Pós-graduação em Medicina Veterinária, Universidade Federal de Santa Maria.

JENKINS, J.R. Avian soft tissue surgery. Part I. In: ACVS VETERINARY SYMPOSIUM, 1992, Miami, Florida. Proceedings... Miami : The American College of Veterinary Surgeons, 1992. p.631-633.

KUZMA, A.B. Avian orthopedics: Fracture management I. In: ACVS VETERINARY SYMPOSIUM, 1995, Miami, Florida. Proceedings... Miami : The American College of Veterinary Surgeons, 1995. p. 249-251.

LEVITT, L. Avian orthopedics. Compendium on Continuing Education for Practicing Veterinarian, v.11, n.8, p.899-929, 1989.

MACCOY, D.M. General principles of avian surgery. Compendium on Continuing Education for Practicing Veterinarian, v.13, n.6, p.989-992, 1991

PUTNEY, D.L. et al. Methylmethacrylate fixation of avian humeral fractures. Journal of the American Animal Hospital Association, v.19, n.5, p.773-782, 1983

REDIG, P.T. A clinical review of orthopedic techniques used in the rehabilitation of raptors. In: FOWLER, M.E. Zoo \& wild animal medicine. Philadelphia : Saunders, 1986. p.388-401.

RUPLEY, A.E. Manual de clínica aviária. São Paulo : Roca, 1999. 582p.

Ciência Rural, v.34, n.6, nov-dez, 2004. 
WAN, P.Y. et al. Comparison of bone healing using polydioxanone and stainless steel intramedullary pins in transverse, midhumeral osteotomies in pigeons (Columba livia). Journal of Zoo and Wildlife Medicine, v.25, p.264-269, 1994

WEST, P.G. et al. Histomorphometric and angiographic analysis of bone healing in the humerus of pigeons. American Journal Veterinary Research, v.57, p.1010-1015, 1996.
WILLIANS, R. et al. A comparative study of treatment methods for long bone fractures. Companion Animal Practice, v.1, n.4, p. 4855,1987

YAMAZOE, $\mathrm{K}$. et al. The reduction of humeral fracture in pigeons with intramedullary poly (methylmethacrylate) and neutralization plate fixation. Journal of Veterinary Medical Science, v.56, p.739-745, 1994. 